\title{
The Breakthroughs of Karl Folkers in Biochemistry and Human Nutrition
}

\author{
Geir Bjørklund ${ }^{1 *}$ and Max Chartrand ${ }^{2}$ \\ ${ }^{1}$ Council for Nutritional and Environmental Medicine, Mo i Rana, Norway \\ ${ }^{2}$ DigiCare Behavioral Research, Casa Grande, AZ, USA
}

*Corresponding author: Geir Bjørklund, Council for Nutritional and Environmental Medicine, Toften 24, 8610 Mo i Rana, Norway, E-mail: bjorklund@conem.org

Received date: April 25, 2017; Accepted date: May 26, 2017; Published date: June 2, 2017

Copyright: ( 2017 Bjørklund G, et al. This is an open-access article distributed under the terms of the Creative Commons Attribution License, which permits unrestricted use, distribution, and reproduction in any medium, provided the original author and source are credited.

\section{History of Science}

Professor Karl August Folkers (Figure 1), a biochemist from the United States, was the head of one of the two research groups, one in England and one in the United States. In 1948, the two groups independently and simultaneously reported the isolation of vitamin B12 [1,2]. Most of Folkers' work was carried out while working at the Merck Company (later Merck Sharp \& Dohme) from 1934 to 1963. His laboratory at Merck was known for isolation, purification, synthesis, and structural determination of many bioactive natural products $[3,4]$, including isolation and determination of the biological structure of various Erythrina alkaloids [4]. They also were the first to describe the synthesis [5,6] and structure [7] of vitamin B6 (pyridoxine, pyridoxal, and pyridoxamine), and the synthesis of pantothenic acid [8], biotin [9], lipoic acid [10], and mevalonic acid [11].

Through his work, the relationship of mevalonic acid in the biosynthesis of cholesterol made it possible for direct applications in controlling cholesterol [4]. Karl Folkers and collaborators later showed that the so-called statins inhibit not only the biosynthesis of cholesterol but also the synthesis of coenzyme Q10 (CoQ10) [4]. But this experiment was performed after he had moved to Texas. It was from this research learned that CoQ10 is necessary as a dietary supplement for patients taking statins to avoid CoQ10 depletion. Karl Folkers and collaborators at Merck also isolated and described the structure of various antimicrobials, especially in the streptomycin group [4]. The team of Folkers performed structural work on penicillin [4].

The search for the anti-pernicious anemia factor relative to vitamin B12 started after the American physician and researcher George $\mathrm{H}$ Whipple (1878-1976) conducted experiments on dogs with induced anemia. Whipple bled the dogs and fed them with food that afforded the fastest recovery from anemia. As a result, Whipple found that foods rich in vitamin B12 provided the most rapid recovery from induced anemia. Based on this research he was able to hypothesize that ingestion of beef liver could be used for the treatment of pernicious anemia. By 1920, he was met with success in proving his hypothesis that adding liver to one's diet became widely recognized as the essential treatment for pernicious anemia. This work continued in 1926 when American medical researchers George R Minot (1887-1950) and William P Murphy (1892-1987) demonstrated that it was the vitamin B12 in beef liver that was essential in treating pernicious anemia [12]. Edwin J Cohn (1892-1953), a physical chemist at Harvard was recruited by Minot to fractionate beef liver to produce concentrates to be tested on patients with pernicious anemia [3]. By 1935, the English chemist Henry D Dakin (1880-1952) and the American hematologist Randolph West (1890-1949), reported the purification process from which to manufacture a fraction, where the concentration of vitamin B12 was enhanced by a factor of $~ 100$ compared with whole liver [3].
Minot, Murphy, and Whipple shared in 1934 the Nobel Prize in Physiology or Medicine for their works on pernicious anemia.

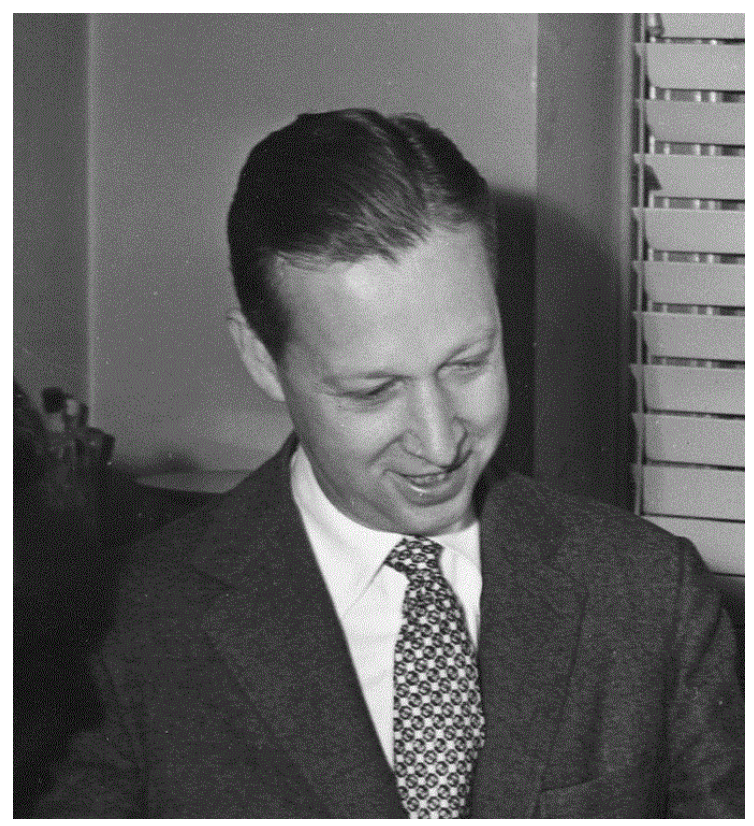

Figure 1: Karl August Folkers (1906-1997) was a US biochemist who made major contributions to the identification and isolation of bioactive natural products, including vitamin B12 and coenzyme Q10.

In the same period, work to try to isolate the anti-pernicious anemia factor was underway in Norway in 1927 by Norwegian physician Olav Mikal Hanssen (1878-1965), who collaborated with pharmacist Per Jensen Laland (1895-1970). Progress in the fractionation work was, however, very slow because they did not have any bioassay, except by testing the various fractions on human subjects. This turned out to be a very slow method, requiring large amounts of material for each subject (Olav Albert Christophersen, personal communication). Per Laland was working as the technical director for the Norwegian pharmaceutical company Nyegaard \& Co., which had much contact with the pharmaceutical company Glaxo in England (Olav Albert Christophersen, personal communication). Before the start of World War II in Norway, a group of researchers went to Norway from Glaxo to learn what Laland had discovered at that point. One may speculate that this happened because both the scientists at Glaxo and Per Laland himself feared that there was a threat that Norway would be attacked and occupied by Germany which actually did happen on 9 April 1940 and none of them wanted the important work of isolation of the anti- 
pernicious factor to be stopped because of such an occupation (Olav Albert Christophersen, personal communication).

Laland's work was indeed interrupted by the German occupation of Norway in 1940, but the researchers at Glaxo were able to continue from where Laland was forced to stop. Nevertheless, progress was still very slow, because they did not have any suitable bioassay except testing of the various fractions on subjects who had pernicious anemia (Olav Albert Christophersen, personal communication).

In 1942, Folkers began a new project to try purifying the antipernicious anemia factor [3]. Folkers was cognizant of the severe difficulties that were met by others who had earlier sought to purify the substance. However, he was also conscious of the fact that more sophisticated and precise approaches in purifying the factor were now available, such as chromatography. To form that standpoint, he assembled a new team of biochemists to tackle this problem [3]. Apparently, it was a much greater challenge than they expected and required several years of little progress [4]. Consequently, Folkers did not publish anything about vitamin B12 until he could finally resolve the challenges involved (Olav Albert Christophersen, personal communication).

A breakthrough occurred in 1947 when the American microbiologist Mary S Shorb (1907-1990) found that the bacterium Lactobacillus lactis Dorner required the anti-pernicious anemia factor as a growth factor [3]. She began to collaborate with Karl Folkers [3], and with a convenient bioassay, it was possible to progress with fractionation at a faster pace than before. The British group (that had started much earlier than Folkers' group and could build upon the work that earlier had been done by Per Laland) and Karl Folkers' group managed to isolate the vitamin at about the same time. Hence, it may be impossible to know today who was first (Olav Albert Christophersen, personal communication).

Before he was forced by the war to interrupt his work, Per Laland had succeeded in making a very concentrated fraction with a rose color. He evidently thought that the color was caused by some contaminant and did not understand at the time that the active substance he was trying to isolate was causing it. If he had understood this, he might have had isolated the vitamin in a much shorter period of time. When his work was interrupted by the war, he stored the highactivity fraction and did nothing more with it until both the American and British groups announced their isolation of the vitamin in 1948. Per Laland then decided once more to have a look at the sample he had left several years earlier and discovered that the vitamin in the meantime had crystallized (Olav Albert Christophersen, personal communication).

In 1955, a nonsaponifiable lipid was isolated by Gerald $\mathrm{N}$ Festenstein and collaborators in the biochemical laboratory of Prof. Richard A Morton (1899-1977), University of Liverpool. The substance was isolated from the intestinal mucosa of horses and was called ubiquinone by Morton [3,13]. A short while later in 1957, at the University of Wisconsin Institute of Enzyme Research, in the section directed by David E. Green (1910-1983), the assistant Frederick L Crane (1925-2016), who later become a professor at the Department of Biological Science, Purdue University, discovered a new quinone in the lipid extracts of mitochondria. Since the quinone was part of the electron transport chain, it was named coenzyme Q $[3,14]$. However due to Folkers' widely recognized skills in structural determination, Crane decided to visit him in Rahway, New Jersey to get help to find the structure of the novel quinone [3]. Within the year, the group of
Karl Folkers' at Merck had found the structure of coenzyme Q [2,3]. The chemist Otto Isler (1910-1992) at Hoffman-La Roche AG in Basel, reached a similar conclusion on samples supplied by Morton $[3,15]$. They then realized that the ubiquinone substance and coenzyme Q were the same substance.

Structural studies following the isolation of vitamin B12 were carried out both in the Merck laboratory and in laboratories in Cambridge and Oxford [3]. Both groups identified the cobalt atom [3]. The Merck team identified the "nucleotide-like" moiety (phosphoribosyl-5, 6-dibenzamideazole) [16]. The Cambridge group identified the central Corrin ring system of pyrroles similar to porphyrin rings [17]. The exact structure of the system was found by X-ray crystallography by the British chemist Dorothy Crowfoot Hodgkin (1910-1994) [18], who in 1937 had already determined the structure of cholesterol and in 1946 penicillin. In 1956, Hodgkin and her group at the University of Oxford published the final structure of vitamin B12 [19]. She received in 1964 the Nobel Prize in Chemistry for her X-ray determinations. In 1969, Hodgkin described the structure of penicillin [20], which had taken 35 years of work to complete.

Although Karl Folkers was never honored with a Nobel Prize for his discoveries, his achievements as a basal biochemical scientist were no less important nor less impressive than those of several other biochemists who have been awarded the Nobel Prize for their discoveries.

During the last years of his life, the most important interest of Folkers' was the question of CoQ10 deficiency in human diseases and the possibility of therapeutic applications of CoQ10 supplementation. He was a coauthor of several articles about this, but he was not equally good as a clinical biochemist as he had earlier been as a basal biochemical scientist. Many of his articles about clinical problems were not good enough from a methodological point of view to prove what he believed he had found. In some instances, Folkers was probably correct but was unable to convince other scientists that he had nothing more than interesting preliminary observations. In other cases, it was more likely that what Folkers and his colleagues believed they had found was not entirely correct.

In 1963, Karl Folkers had left Merck to be president and chief executive officer of the Stanford Research Institute, which included a courtesy position as professor of chemistry at Stanford University [3]. In 1968, however, he left the appointment at Stanford to be a professor of chemistry at the University of Texas and director of the newly founded Institute for Biomedical Research [3]. After he had come to Texas, Folkers was invited by the endocrinologists Andrew V Schally (born 1926) and Cyril Y Bowers to work on the structure and synthesis of the hypothalamic hormone thyrotropin-releasing hormone (TRH), which they had isolated [4]. In 1969, the research team provided the structure and synthesis of TRH, which was the first discovered hypothalamic hormone [4]. Andrew V Schally continued the research on "the peptide hormone production of the brain". For his research, Schally shared in 1977 the Nobel Prize in Physiology or Medicine with Rosalyn Yalow and Roger Guillemin [21].

Karl Folkers probably left Stanford due to such an extensive amount of administrative duties that it limited his possibilities for personal research [3]. He wanted to be part of a research environment where it was possible for him to continue the investigation of the therapeutical properties of CoQ10 [3]. Folkers and colleagues found reduced tissue concentrations of CoQ10 in patients with various chronic disorders, 
Page 3 of 4

which they believed were a sign of inadequate biosynthesis of CoQ10 [4]. They also felt that they saw beneficial effects of oral supplementation with CoQ10 in a variety of diseases: muscular dystrophy, periodontal disease, hypertension, and cardiomyopathy [4].

Sadly, many of Karl Folkers' studies were in collaboration with physicians who were uncritical regarding clinical investigations. The medical profession has not generally accepted this aspect of his work, which comprises some 300 papers [3]. It is possible that the limited lack of success of this clinical demonstration was not only a consequence of the studies not being good enough from a methodological point of view, but may also have been due to increased oxidative stress in several different diseases, which may have been a consequence of tissue CoQ10 depletion as a result of abnormally enhanced degradation rather than because the biosynthesis was inhibited.

If CoQ10 is depleted, whether because of enhanced degradation of inhibited biosynthesis or other means, it can in most cases lead to harmful consequences for individuals. Nevertheless, this does not conclusively mean that CoQ10 is central in the pathogenesis of the disease. As far as the antioxidant nutrients are concerned, it is highly possible that there will be depletion also of other nutrients or cofactors, e.g. glutathione, which might be even more important than CoQ10 depletion relative to some of the diseases concerned (e.g. cardiomyopathy associated with cardiac failure, and periodontal disease). It is, therefore, possible that in most cases patients should be given CoQ10 together with other nutrients like in the Adjuvant Nutritional Intervention in Cancer (ANICA) trial [22] rather than as monotherapy.

It may likewise be said, in Folkers defense that looking at his list of publications from his years in Texas, one may gain the impression that his research strategy was to try to present preliminary overviews of the possible usefulness of CoQ10 in a wide range of different diseases, rather than delving into the more tedious work that would be encountered in more thorough studies that demonstrated clinical efficacy. He may perhaps deliberately have sacrificed methodological perfection when conducting more preliminary survey work, because it would have taken too much time and resources for each subproject. This is, of course, a research strategy entirely analogous to what oil companies are doing when a large previously unexplored area is opened for geophysical and geological studies in the search for oil or gas. They also want to make a more general wide-mesh survey of a large area before they proceed with the areas that look most promising (Olav Albert Christophersen, personal communication).

Karl Folkers and his collaborators also studied the blood levels of CoQ10 in patients with cancer $[23,24]$ and patients with HIV disease [25]. Consequently, they found lower than normal average blood levels of CoQ10 in both groups. A few HIV patients in the transition stage between asymptomatic HIV disease and AIDS (which was then called AIDS-related complex) had shown a-"striking" clinical response to therapy with CoQ10 $[25,26]$. Two patients had survived four to five years with AIDS-related complex without any signs of infection or adenopathy on the continued treatment with coenzyme CoQ10 [26].

Finally, Folkers drew attention to the probable role of CoQ10 in various immunological functions [25,26]. In one study, 14 individuals reacted positively during CoQ10 treatment with increased CD4+/ CD8+ T-lymphocyte ratio and elevated blood concentrations of CoQ10 ( $<<0.001)[26]$. Also, CoQ10 supplementation had been found to significantly increase the levels of IgG in subjects [25]. Karl Folkers and collaborators also reported about ten case stories that indicate that CoQ10 supplements might be helpful for at least some cancer patients. They estimated that the therapy with CoQ10 increased the expected survival of their cancer patients with 5-15 years. No significant adverse effects were noted in these cases [25].

\section{References}

1. Smith EL, Parker LFJ (1948) Purification of the anti-pernicious anemia factor. Biochem J 43: viii.

2. Wolf DE, Hoffman CH, Trenner NR, Anson DH, Shunk CH, et al. (1958) Coenzyme Q. Structural studies coenzyme Q group. J Am Chem Soc 80: 4752 .

3. Olson RE (2001) Karl August Folkers (1906-1997). J Nutr 131: 2227-2230.

4. Shive W (2002) Karl August Folkers, September 1, 1906 - December 9, 1997. Biogr Mem Natl Acad Sci 81: 100-114.

5. Harris SA, Folkers K (1939) Synthesis of vitamin B6. J Am Chem Soc 61: 1245-1249.

6. Harris SA, Heyl D, Folkers K (1944) The vitamin B6 group. The structure and synthesis of pyridoxamine and pyridoxal. J Am Chem Soc 66: 2088-2092.

7. Harris SA, Stiller ET, Folkers K (1939) The structure of vitamin B6. J Am Chem Soc 61: 1242-1244.

8. Stiller ET, Harris SA, Finklestein J, Keresztesy JC, Folkers K (1940) The total synthesis of pantothenic acid. J Am Chem Soc 62: 1785-1790.

9. Harris SA, Wolf DE, Mozingo R, Folkers K (1943) Synthetic biotin. Science 97: 447-448.

10. Walton E, Wagner AF, Bachelor FW, Peterson LH, Holly JF, Folkers K (1955) The synthesis of alpha-lipoic acid and its optical antipode. J Am Chem Soc 77: 5144-5146.

11. Wolf DE, Hoffman CH, Aldrich PE, Skeggs HR, Wright LD, Folkers K (1956) beta-Hydroxy-beta-methyl-gamma-valerolactone (mevalonic acid) a new biological. J Am Chem Soc 4498-4499.

12. Minot GR, Murphy WP (1926) Treatment of pernicious anemia by a special diet. J Am Med Assoc 87: 470-476.

13. Festenstein GN, Heaton FW, Lowe JS, Morton RA (1955) A constituent of the unsaponifiable portion of animal tissue lipids. Biochem J 59: 558-566.

14. Crane FL, Hatefi Y, Lester RL, Widmer C (1957) Isolation of a quinone from beef heart and beef heart mitochondria. Biochim Biophys Acta 1957; 25: 220-221.

15. Morton RA, Gloor U, Schindler O, Wilson GM, Chopard-dit-Jean LH, et al. (1958) Structure of ubiquinone from swine heart (in German). Helv Chim Acta 4: 2343-2357.

16. Brink NG, Holly FW, Shunk GH, Peel EM, Cahill JT, et al. (1950) Vitamin B12 IX 1-alpha-D-ribofuranosido-5,6-dimethyl benzimidazole, a degradation product of vitamin B12. J Am Chm Soc 72: 1866.

17. Cannon JR, Johnson AW, Todd AR (1953) Structure of vitamin B12; a crystalline nucleotide-free degradation product of vitamin B12. Nature (Lond.) 74: 168-169.

18. Brink NG, Hodgkin DC, Lindsey J, Pickworth J, Robertson JH, et al. (1954) X-ray crystallographic evidence on the structure of vitamin B12. Nature (Lond.) 74: 1169-1171.

19. Hodgkin DC, Kamper J, Mackay M, Pickworth J, Trueblood KN, et al. (1956) Structure of vitamin B12. Nature (Lond.) 78: 64-66.

20. Ferry G (1998). Dorothy Hodgkin: A Life. Granta Books, London.

21. http://www.nobelprize.org/nobel_prizes/medicine/laureates/1977/ schally-facts.html.

22. Bjørklund G (2015) The Adjuvant Nutritional Intervention in Cancer (ANICA) trial. Nutr Cancer 67: 1357-1360.

23. Folkers K (1996) Relevance of the biosynthesis of coenzyme Q10 and of the four bases of DNA as a rationale for the molecular causes of cancer and a therapy. Biochem Biophys Res Commun 224: 358-361. 
Citation: Geir Bjørklund, Max Chartrand (2017) The Breakthroughs of Karl Folkers in Biochemistry and Human Nutrition. J Nutr Disorders Ther 7: 213. doi:10.4172/2161-0509.1000213

Page 4 of 4

24. Folkers K, Osterborg A, Nylander M, Morita M, Mellstedt H (1997) Activities of vitamin Q10 in animal models and a serious deficiency in patients with cancer. Biochem Biophys Res Commun 234: 296-299.

25. Folkers K, Brown R, Judy WV, Morita M (1993) Survival of cancer patients on therapy with coenzyme Q10. Biochem Biophys Res Commun 192: 241-245.
26. Folkers K, Hanioka T, Xia LJ, McRee JT Jr, Langsjoen P (1991) Coenzyme Q10 increases T4/T8 ratios of lymphocytes in ordinary subjects and relevance to patients having the AIDS related complex. Biochem Biophys Res Commun 176: 786-791. 